\title{
Administração PÚblica, FINANCIAMENTO E CONCRETIZAÇÃO DOS DIREITOS FUNDAMENTAIS
}

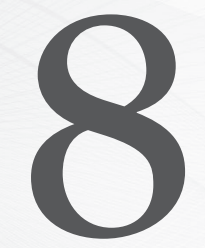

\author{
Public Administration, financing and implementation \\ of fundamental rights
}

\section{Julio Pinheiro Faro}

Mestre em Direitos e Garantias Fundamentais pela Faculdade de Direito de Vitória (FDV). Professor de Introdução ao Estudo do Direito, Direito Financeiro, Direito Tributário e Direito Processual Tributário na Estácio de Sá (Vitória/ES). Professor-Coordenador do Grupo de Estudos em Políticas Públicas e Desigualdades Sociais na FDV. Diretor Secretário-Geral da Academia Brasileira de Direitos Humanos (ABDH). Pesquisador vinculado ao Programa de Pós-Graduação Stricto Sensu da FDV. Advogado e Consultor Jurídico.

Recebido em: 29.08.2012 Aprovado em: 07.09.2012

ÁreA do DIREITO: Administrativo; Constitucional

Resumo: A concretização de direitos fundamentais tem um custo com o qual a sociedade deve arcar mediante o pagamento de tributos. Com o pagamento de tributos são formados recursos públicos que serão geridos pelo Estado, por meio da Administração Pública, a qual deverá alocar e investir esses recursos tanto para manter o funcionamento do maquinário estatal quanto para concretizar direitos. Assim, o Estado funciona como uma empresa gestora de recursos públicos, que devem, principalmente, ser utilizados para, mediante ações prestacionais, concretizar
ABSTRACT: The real effectiveness of fundamental rights has a cost with which the society must bear with through tax payment. With the payment of taxes are generated public resources which will be managed by the State, through the Public Administration, which must allocate and invest such resources both to maintaining the state machinery operation and to giving effectiveness to rights. Then, the State works as a management company of public resources, which must, mainly, be employed for, through public policies, give effectiveness to social 
direitos sociais cujo exercício permite o melhor exercício das liberdades. Observando-se esses aspectos subjaz uma imensa gama de questões que ainda são objeto de discussão pelos juristas, como o "mínimo existencial", a "reserva do possivel" e a "proibição do retrocesso social". Sem pretender esgotar o assunto, este trabalho traz algumas reflexões sobre essas questões com o intuito de trazer um contributo para repensar o tema da concretização dos direitos fundamentais. Assim, apresenta-se uma breve contribuição sobre o papel da Administração Pública contemporânea quanto ao uso dos recursos arrecadados para a concretização e manutenção dos direitos fundamentais.

Palavras-chave: Direitos fundamentais - Mínimo existencial - Reserva do possível - Irreversibilidade dos direitos fundamentais - Administração Pública. rights, which exercise allows a better fruition of liberties. Looking for such observations, it raises a variety of questions which still being in discussion by lawyers, as the "existential minimum", the "reserve of the possible", and the "social setback prohibition". Without the animus of exhausting such issues, this study brings some reflections on those three questions intending to bring a contribution for rethinking the fundamental rights real effectiveness issue. Thus, it is presented a succinct contribution of the role played by the contemporaneous Public Administration on the employment of the collected resources for giving effectiveness to and for maintaining the fundamental rights.

KeYwords: Fundamental rights - Existential minimum - Reserve of the possible - Prohibition of setback - Public Administration.

Sumárıo: 1. Introdução - 2. Financiando os direitos fundamentais - 3. Observando as necessidades humanas básicas - 4. Protegendo os direitos mínimos - 5. Concretizando os direitos fundamentais - 6. Conclusões - 7. Referências bibliográficas.

\section{INTRODUÇÃO}

A concretização ${ }^{1}$ dos direitos fundamentais custa dinheiro, ${ }^{2}$ de modo que a sociedade deve financiá-la através do pagamento de tributos, abastecendo os cofres públicos, ${ }^{3}$ geridos pelo Estado, através da Administração Pública, que alocará e investirá esse dinheiro na própria sociedade. Neste sentido, tem-se

1. Artigo publicado originariamente em espanhol, sob o título "Administración Pública, realización y financiación de los derechos fundamentales", em Del Real, Enríquez y Rodríguez (no prelo). Agradeço por toda ajuda aos amigos e Professores Alberto del Real, Bruno Costa Teixeira, Giuseppe Martinico, José Emílio Medauar Ommati, Flávio Quinaud Pedron, Adriano Sant'Ana Pedra, Leonardo Martins, Ingo Wolfgang Sarlet, António José Avelãs Nunes, Antonio-Enrique Pérez Luño e Ana Maria D’Ávila Lopes.

2. Este entendimento parece ser generalizado e pacífico, podendo-se citar exemplos de literatura a respeito: Immordino; Pagano (2004), Posner (1996), Holmes; Susntein (1999), Amaral (2001) e Galdino (2005).

3. Neste mesmo sentido, por exemplo: Scaff (2007) e Ataliba (2009). 
que o Estado funciona como uma empresa gestora de toda essa verba, agora pública, devendo reservar pequena parte para a manutenção do aparato estatal e aplicar o restante na concretização dos direitos fundamentais, por meio de ações prestacionais, realizadoras dos direitos sociais, econômicos e culturais (doravante chamados direitos sociais), cujo exercício permite o melhor desfrute dos direitos à liberdade (daqui por diante referidos como liberdades) (CANOTILHO, 2003, p. 473).

Observando tão só estes aspectos surge uma imensa gama de questões ainda controvertidas, especialmente na práxis, dentre elas as três seguintes: o mínimo existencial, a reserva do possível e a irreversibilidade da concretização dos direitos fundamentais (ou proibição do retrocesso social). Sem pretender esgotar o assunto, este pequeno trabalho trata brevemente sobre essas questões com o intuito de se posicionar como um contributo para pensar a concretização dos direitos fundamentais. Neste passo, apresenta-se uma breve contribuição à reflexão acerca do papel da Administração Pública contemporânea quanto ao uso dos recursos arrecadados para a concretização e para a manutenção dos direitos fundamentais.

\section{Financiando os direitos fundamentais}

A relação estabelecida entre o dever de pagar tributos e a concretização dos direitos fundamentais parece simples. Os direitos representam o que o Estado deve proporcionar aos indivíduos, enquanto os deveres ${ }^{4}$ têm relação com o que os indivíduos devem proporcionar ao Estado e à sociedade (CASAlta Nabais, 2004, p. 65). A função básica do pagamento de tributos, embora possa significar algum tipo de limitação ao exercício de determinados direitos ${ }^{5}$ através da redução de orçamentos individuais, ${ }^{6}$ é de que a sociedade financie o Estado. Deste modo, o Estado poderá tanto funcionar quanto estabelecer e manter prestações concretizadoras de direitos sociais, cuja efetivação permite

4. Sobre deveres fundamentais, por exemplo: Peces-Barba Martínez (1987) e Rubio LlORENTE (2001).

5. Tavares (2008, p. 488) e Torres (2003, p. 55) observam que há direitos que, ao serem exercidos, ensejam a possibilidade de serem tributados pelo Estado, promovendo, então, sua autolimitação e a limitação do poder tributário estatal.

6. É o caso, por exemplo, do imposto sobre a renda, onde parte da renda bruta do indivíduo é tributada para fins de financiamento do Estado, provocando uma diminuição no orçamento individual disponível para o exercício de alguma liberdade, diminuindo uma possível poupança do indivíduo. 
o melhor exercício das liberdades, ou ao menos dos direitos considerados minimamente necessários para uma existência humana digna.

Tem-se, portanto, que a concretização de direitos depende de prestações estatais, e que estas dependem, em parte, do cumprimento do dever de pagamento de tributos. Assim, pode-se dizer que os indivíduos, de acordo com suas possibilidades, atuam em cooperação para dar ao Estado os meios para atingir um de seus fins, permitindo o desfrute de direitos pela sociedade. De aí se poder dizer que o pagamento de tributos advém da necessária cooperação dos indivíduos que compõem uma sociedade, a fim de que o Estado, gerenciando o dinheiro arrecadado, remunere funcionários e invista maciçamente na própria sociedade, concretizando os direitos fundamentais de seus membros, isolada e coletivamente considerados.

Esse investimento estatal direcionado à sociedade tem como foco principal a realização dos direitos sociais. Isso se explica pelo fato de serem esses os direitos que possuem basicamente a função de assegurar as liberdades e o tratamento igualitário entre os membros da sociedade (NEUner, 2006, p. 150-153). Disso decorre que a concretização dos direitos tem seu custo para o erário (AFonso Da Silva, 2008, p. 591), do que o custo de concretização dos direitos sociais é maior, já que as liberdades dependem muito mais, embora não só, da inatividade estatal para serem exercidas. Noutros termos, uma vez realizados os direitos sociais, os indivíduos têm autonomia para exercer ou não suas liberdades. E é nesta senda que se insere o discurso da reserva do possível.

A expressão "reserva do possível", cunhada pelo Tribunal Constitucional Federal alemão e adotada pela doutrina alemã, tem o sentido de que a sociedade deveria delimitar a razoabilidade da exigência de determinadas prestações sociais, a fim de impedir o uso dos recursos públicos disponíveis em favor de quem deles não necessita (MARTINs, 2005, p. 663-664). Em outras palavras, pela doutrina da reserva do possível, o Estado deve concretizar a igualdade através de políticas públicas voltadas para aquela parcela da sociedade que delas necessita e, por extensão, que os recursos públicos voltados para o custeio dessas prestações limitem-se à garantia e manutenção das necessidades básicas dos indivíduos.

$\mathrm{Na}$ contramão da teoria original, verifica-se a associação da reserva do possível com a questão de que a concretização de direitos só é possível enquanto houver dinheiro no erário (CAnotilho, 2003, p. 481; Canotilho, 1998, p. 46). Associação esta decorrente da referência de que estes direitos, em geral, constituem-se como bens ou decorrem da prestação de serviços que possuam algum valor econômico (Prieto Sanchis, 1995, p. 15). Contudo, é preciso prestar atenção para o fato de que os direitos apenas se submetem à reserva 
do possível em relação àquilo que ultrapasse as necessidades humanas básicas. Assim, o mau uso do argumento da reserva do possível resulta na postergação da realização dos direitos fundamentais, promovendo uma lesão a tais direitos decorrente da inércia da concretização e da má gestão dos recursos públicos (VAz, 2009, p. 35) e, ainda, das más opções políticas e orçamentárias.

Em síntese, como a concretização dos direitos sociais custa dinheiro, a reserva do possível só pode ser invocada, adequadamente, para situações que extrapolem as necessidades vitais básicas, afastando-se o argumento de que há uma infinidade de necessidades humanas e uma escassez de recursos financeiros para atendê-las (SCAFF, 2006, p. 148). Neste passo, o verdadeiro sentido do discurso da reserva do possível é que os recursos financeiros estatais devem ser empregados para atender o que é básico, e depois o que não é, situação esta que, infelizmente, o Estado não observa (Pinheiro FAro, 2008; Krell, 1999, p. 241-242; Freire JR., 2005, p. 74).

\section{ObSERVANDO AS NECESSIDADES huMANAS BÁSICAS}

A inobservância pelo Estado de que o financiamento realizado pela sociedade volta-se à concretização do desenvolvimento humano e à expansão das liberdades (SEN, 2007, p. 17), ao atendimento das necessidades humanas básicas, traz o esvaziamento do erário, de maneira que os recursos arrecadados e outrora disponíveis encontram-se esgotados quando se trata de concretizar o mínimo existencial. Situação esta que não poderia ocorrer sob o correto uso da ideia de reserva do possível (Zockun, 2009, p. 54), e sim apenas sob o seu uso deturpado ao argumento de que não é possível a concretização porque as necessidades humanas são infinitas.

A questão das necessidades humanas básicas é controvertida, especialmente no que diz respeito a que necessidades fariam parte do mínimo existencial. Fazer uma lista não se constitui, seguramente, no problema mais difícil a ser enfrentado, mas criar uma lista fixa e imutável (SEN, 2005, p. 158), a fim de que se possa requerer ao Estado a concretização de tais itens. Uma vez firmado esse rol, surge outro problema, estabelecer a existência e como será respeitada uma prioridade entre seus elementos, de modo que se possa verificar se o Estado tem implantado as políticas públicas certas e na medida necessária para o seu correto aproveitamento pela sociedade.

É preciso, portanto, que o Estado não confunda as necessidades humanas e os diversos outros conceitos que lhes são próximos, como desejos, instintos, interesses, aspirações etc. (De Lucas; AÑón Roig, 1990, p. 60). Aliás, é importante que se diga, desde logo, que o uso do termo "necessidades", para 
expressar aquilo que não pode faltar, é enganoso, já que as pessoas têm apenas ideias sobre aquilo que necessitam, ou, ainda, sobre o que é prioritário para suas vidas e em que grau (Walzer, 2003, p. 88).

A reserva do possível, em sua acepção original, encaixaria melhor aqui, ou seja, na formação de uma lista de prioridades cuidadosamente escolhidas, após uma seleção detida, devido à escassez dos recursos para sua concretização (Walzer, 2003, p. 88). Deve-se, portanto, entender as necessidades como aquilo que é prioritário, cuja concretização não pode faltar dentro de uma sociedade em determinados tempo e espaço, trata-se, então, do conteúdo essencial formador ou delimitador do mínimo existencial, ${ }^{7}$ composto, assim, por condições materiais mínimas que devem ser concretizadas e protegidas porque têm o condão de assegurar a todos os membros daquela sociedade o seu desenvolvimento enquanto seres humanos, isto é, com dignidade e podendo exercer sua autonomia (Sarlet; Figueiredo, 2008, p. 150).

Seria, entretanto, impraticável, para que o conjunto de necessidades seja o mesmo, que se considerassem as várias diferenças intersubjetivas, de maneira que, para tornar real e possível essa igualdade, se idealiza que todas as pessoas sejam iguais, a fim de que se possa trabalhar melhor com o conceito em tela. Tem-se, pois, uma situação hipotético-pragmática, útil para formar senão uma lista de necessidades, pelo menos direcionar como se estabelecer tal rol, já que assim é possível que sejam feitas escolhas genéricas e objetivas sobre que necessidades são realmente prioritárias, isto é, imprescindíveis para a persecução de um plano de vida baseado no atendimento de níveis mínimos de dignidade (ZimMERLing, 1990, p. 41). Aqui, no entanto, não se ocupa de saber que necessidades ocuparão essa lista, e sim apontar que, sejam quais forem, cada uma delas possui um peso, ou grau de prioridade, que o Estado deve observar ao realizar políticas públicas, a fim de concretizar as oportunidades (direitos sociais) que permitirão a expansão do exercício da autonomia (liberdades) dos indivíduos (Robeyns, 2005, p. 94).

\section{Protegendo os diReItos Mínimos}

A concretização de oportunidades para o melhor exercício de liberdades depende, pois, da existência de todo um maquinário institucional que condense

7. Cumpre observar que conteúdo essencial e mínimo existencial não são sinonímias. O conteúdo essencial é uma garantia limitadora da atividade estatal excessiva ou deficiente ou de sua inatividade. O mínimo existencial é uma garantia ampliadora dos direitos fundamentais, obrigando o Estado a aplicar seus recursos para concretizar oportunidades que formam o seu conteúdo essencial. Sobre isso, ver: LOPES (2004) e BALBONI (2001). 
e direcione os recursos formados pela arrecadação de tributos junto à sociedade (Immordino; PAgAno, 2004, p. 85), poupando-os para utilizar naquilo que se apresentar de utilidade imediata, diga-se prioritário. Esse maquinário é o Estado, representado pela Administração Pública, que, além de arrecadar da sociedade a verba para financiamento das políticas públicas, é "capaz de influenciar o uso de fatores de produção através de decisões administrativas", hábeis, aliás, à "obtenção de certas coisas por um menor custo do que as empresas privadas" (COASE, 1960, p. 17). Assim é que a Administração Pública deve, após adotar uma lista de necessidades ordenadas conforme o seu grau de prioridade, alocar com eficiência os recursos arrecadados disponíveis para promover a concretização das oportunidades mínimas que todo indivíduo deve possuir. Isso permite dizer que a possibilidade de realização do mínimo existencial depende de que o Estado possua uma reserva de recursos, e este é, por sinal, o verdadeiro sentido daquilo que se cunhou "reserva do possível" (SARLET, 2008; SCHÄFER, 2005, p. 67).

Dispor de recursos para a promoção do conteúdo essencial não significa que as oportunidades devam todas ser oferecidas de uma só vez. Ao contrário, os gastos estatais devem ser planejados. Ora, se não há recursos suficientes para concluir uma política pública, deve-se ao menos começá-la (FREIRE JR., 2005, p. 74), aplicando-se os recursos disponíveis. E, quando houver nova disponibilidade, injetar mais recursos em tais políticas, continuamente, para que as prestações sociais sejam expandidas (СAnотіLHo, 1998, p. 47), e, assim, as oportunidades e, ainda, o exercício das liberdades.

Essa continuidade, que deveria ser ininterrupta, traz à baila a questão da proibição da reversibilidade da concretização dos direitos fundamentais. Esta vedação estabelece que aquilo que já foi concretizado deve ser pelo menos mantido, em virtude do necessário respeito ao mínimo existencial, e, assim que possível, ser maximizado. Impõe-se, portanto, à Administração Pública o dever de não violar, através de sua atividade ou inatividade, o mínimo existencial (DE Conto, 2008, p. 100). Entende-se, então, a irreversibilidade como uma garantia cujo objetivo é manter a concretização de direitos, especialmente aqueles de natureza prestacional. E, neste sentido, há íntima relação entre a reserva do possível em sua acepção original e a vedação da reversibilidade da concretização de direitos fundamentais, já que ambas se referem àquilo que o indivíduo pode razoável e racionalmente exigir da sociedade (KRELL, 2002, p. 52; QUEIROZ, 2006, p. 68).

A finalidade do instituto é evitar que o Estado, através de qualquer de seus Poderes, provoque uma situação de possível retrocesso social. Daí a nomenclatura habitualmente utilizada: proibição do retrocesso social. Assim, uma vez concretizados determinados direitos, estes assumem uma natureza híbrida, 
vinculando o Estado à sua necessária manutenção e impedem (DERBLI, 2007, p. 176) que os entes estatais ajam com excesso ou no sentido de promover sua redução ou anulação.

Neste passo, a vedação de reversibilidade tem a ver com a proibição de excesso e com a proibição de proteção deficiente. Pela vedação de excesso, a Administração Pública não pode se valer de meios retrocessivos que, mesmo que não atinjam direitos já concretizados, podem promover uma involução dentro do âmbito de efetivação e proteção dos direitos, devido a uma intervenção além do necessário. Pela vedação da proteção deficiente, a Administração Pública tem o dever de realizar prestações direcionadas à concretização do conteúdo essencial das necessidades humanas básicas (Bernal Pulido, 2007, p. 807; De Conto, 2008, p. 100; Barnes VÁzquez, 1994, p. 510; Ávila, 2007, p. 145-149). Em breve síntese, a Administração Pública tem o papel de elaborar, de implantar e de manter políticas públicas que concretizem com eficiência os direitos que se considerem prioritários, maximizem-nos e impeçam a ingerência estatal na autonomia das pessoas.

O objeto das políticas públicas são especialmente os direitos fundamentais sociais, que, por pertencerem ao ramo jurídico constitucional, e, assim, público, vinculam diretamente os órgãos estatais, dentre eles a Administração Pública. Assim, não se pode argumentar, que a inexistência de norma regulamentadora ou que a falta de dotação orçamentária ou de previsão de gasto impeça a concretização imediata de um direito social através da prestação estatal cabível (MARTins, 2004, p. 96-98), ainda mais quando se estiver em tela a concretização das necessidades básicas.

O problema da inexistência de normas tem no preenchimento de lacunas pelo intérprete e aplicador do direito a sua solução, a qual, porém, não é arbitrária, ${ }^{8}$ devendo-se respeito àquilo que for prioritário. Já o problema da falta de previsão de recursos encontra solução no controle do poder discricionário da Administração Pública (SARLEt; Figueiredo, 2008, p. 150), ou seja, de que em matéria do conteúdo essencial dos direitos fundamentais, não pode o Estado valer-se simplesmente de critérios como a conveniência e a oportunidade para realizar políticas públicas; vale dizer, a Administração Pública por vincular-se aos direitos fundamentais e às normas constitucionais não pode tomar decisões livremente, devendo, portanto, respeito à vontade do constituinte (SARLET, 2009, p. 447).

8. Assim, o Judiciário não pode atuar para resolver todas as carências de direitos das pessoas, com base em uma suposta violação da dignidade da pessoa humana, sempre alegada e, em geral, para forçar a obtenção de tutela favorável a qualquer direito que se diga possuir. Neste sentido: AfONSO da Silva (2009, p. 78, nota 33). 


\section{COnCREtizando OS DiREITOS FUndAMENTAIS}

Cuida-se, então, do necessário controle dos atos administrativos sobre políticas públicas de concretização de direitos fundamentais, tanto para as oportunidades quanto para o exercício da autonomia.

Os atos administrativos constituem-se, em rápida síntese conceitual, nas declarações unilaterais da Administração Pública, para concretizar, através de serviços públicos, ${ }^{9}$ os comandos das normas jurídicas. Tais declarações unilaterais vinculam-se, principalmente, ao interesse público e ao ordenamento jurídico.

É bastante comum, quando se trata sobre atos administrativos, falar-se em atos vinculados e atos discricionários. ${ }^{10}$ No entanto, propriamente não há que se fazer a classificação, já que todos os atos administrativos são vinculados, isto é, a norma que estabelece que se pratique um ato administrativo tem em seu espírito a finalidade de que este atenda, na forma da lei e com eficiência, o interesse público. Logo, não se pode dizer que a discricionariedade se contrapõe à vinculatividade (BANDeira De Mello, 2004, p. 18), pois, do contrário, o ato discricionário seria o mesmo que ato desvinculado, ou até arbitrário.

Portanto, ato administrativo discricionário desvinculado inexiste. O que há é a possibilidade de escolha dos meios para se atingir uma finalidade, com eficiência e dentro das limitações legais, constitucionais e orçamentárias. Isto é, a Administração Pública pode escolher como realizar uma prestação pública, desde que ela alcance o fim que o sistema jurídico lhe impõe, motivando, por certo, suas escolhas, com clareza e congruência.

9. Há, entre os autores, dificuldade em conceituar serviços públicos. Um conceito útil ao fim deste ensaio é o de que são prestações estatais com o objetivo de concretizar direitos fundamentais sociais aos indivíduos, para poderem melhor exercer sua autonomia (liberdades). Isto é, prestam-se utilidades econômicas que, mesmo que direcionadas ao atendimento de necessidades coletivas, beneficiam diretamente aos indivíduos, já que estes têm também essas necessidades, contribuindo para a redução das desigualdades sociais e econômicas, conforme as opções dos indivíduos em exercer ou não e de que forma a sua autonomia (ARAGÃo, 2007, p. 684-685).

10. Tradicionalmente diz-se que os atos vinculados não permitem à Administração proferir qualquer tipo de juízo quanto à prática do ato, enquanto os discricionários lhe permitem proferir juízos quanto à prestação que melhor cumprirá o disposto na Constituição e/ou na lei. BANDeIRA DE Mello (2008, p. 9 e 18) aponta que a distinção não se refere ao ato em si, mas à competência para apreciar seus elementos, de modo que se pode concluir que todos os atos são vinculados, distinguindo-se a competência em vinculada e discricionária. Para uma crítica à distinção e à concepção dos atos, ver: Омматі (no prelo). 
Pode-se tratar o problema como uma questão de intensidades. Nos extremos, abstratamente, há os tipos puros de vinculatividade e de discricionariedade, que, iniludivelmente, não se verificam na prática (Freitas, 2009, p. 82). No ponto central de encontro entre esses dois vetores há sua confusão, ou seja, a impossibilidade de identificar com clareza que tipo de ato deva ser praticado, aqui há algo com rara ocorrência prática. Entre os extremos e as proximidades desse ponto estão os vários tipos de atos administrativos, separados em vinculados e discricionários.

Para facilitar o entendimento, fala-se em padronização, enquanto os atos que pontilham o vetor vinculado ensejam padrões - isto é: independente de quem os vá realizar alcançar-se-á a finalidade senão pelos mesmos meios, por meios parecidos -, os atos que pontilham o vetor discricionário dificultam ou impedem a formação de padrões - é dizer: dependendo de quem os vá realizar alcançar-se-á um fim por diversos critérios (Реixoto, 2006, p. 151). Neste passo, embora os dois vetores estejam vinculados ao interesse público e haja nos dois casos inafastável necessidade de que as escolhas feitas sobre os meios que melhor atingiriam uma finalidade sejam devidamente motivadas, a fim de ver ausentes os excessos, as deficiências ou a inoperância, ou de impedir a arbitrariedade, e, ainda, de verificar o correto emprego de recursos públicos, verificar-se-á que se confere certa margem de liberdade à Administração Pública, tanto num tipo de ato como no outro.

Esta liberdade de escolha é conferida pelas normas jurídicas já estabelecidas. Ou seja (Freitas, 2009, p. 36): há casos em que a própria ordem jurídica delimita o juízo administrativo ao mínimo possível sobre como atingir uma finalidade, enquanto, noutros, essa mesma ordem permite um juízo maior de decisão sobre que meios adotar (Di Pietro, 2007, p. 6). Observa-se, pois, que tanto na primeira situação - a dos atos vinculados - quanto na segunda - a dos atos discricionários - há liberdade de eleição, fundamentada, de caminhos. E isso acontece porque há casos em que há mais de uma maneira adequada para atender ao interesse público, e, também, casos em que a lei não fornece os elementos necessários - porque as situações fáticas são várias e ao legislador não se pode requerer que preveja todos os possíveis casos - para se chegar à melhor solução. Portanto, segue-se o padrão legal e constitucional, daí se poder dizer haver vinculação não só ao interesse público, mas também à legalidade, e que há discricionariedade quando se decide como fazer, ou seja, como fazer da maneira mais apropriada para se atingir o melhor resultado possível.

As políticas públicas decorrem, portanto, e diante do exposto, de atos administrativos, que podem ser vinculados ou discricionários, podendo, assim, depender ou não de uma decisão dentre várias soluções apropriadas e cabíveis 
da Administração Pública para concretizar, com eficiência, os comandos das normas jurídicas, dentre elas as normas de direitos fundamentais, especialmente os sociais. Neste passo, as políticas públicas são vistas, aqui, como serviços públicos prestados pelo Estado, por meio da Administração Pública ou de seus delegatários, para promover direitos fundamentais. Mas não só, ao que aqui se entende, o conceito de políticas públicas é mais amplo que o de serviços públicos (Bucci, 1997, p. 90) naquilo que se refere à realização do objeto da política pública, por haver uma harmonização entre as atividades desenvolvidas pela Administração e seus delegatários e pelas entidades de natureza privada ${ }^{11}$ em prol da concretização de direitos.

As políticas públicas buscam fundamento primordial na Constituição e, quando houver, nas leis que lhes regulamentam. Assim, se cabe ao Poder Legislativo editar determinada lei, mesmo que a iniciativa de tal espécie normativa tenha partido de outro Poder, cabe à Administração Pública, efetuar prestações com eficiência e também as regulamentar - no caso de prestações por entes privados, delegatários ou prestadores de serviços compartidos -, seguindo, sempre, as diretrizes e limites apontados pelo Legislativo e os comandos constitucionais, a fim de concretizar direitos fundamentais.

Essa atividade prestacional - e não poderia ser diferente - está sujeita ao controle formal e, especialmente, material, sobremaneira naquilo que diz respeito à contemplação de sua finalidade - isto é, a viabilização do exercício das liberdades através da realização, pelo Estado, dos direitos fundamentais sociais - e naquilo que tem a ver com a motivação do ato. O chamado controle da Administração Pública ou, ainda, o controle das políticas públicas concretizadoras de direitos fundamentais, tem como objetivo garantir que a prestação de políticas públicas seja eficiente, respeitando-se os princípios e finalidades que o ordenamento jurídico impõe a esta atuação (BACEllar Filho, 2007, p. 34), evitando-se, com isso, desvios que possam vir a ocorrer, como, por exemplo, desvios de finalidade e de recursos públicos.

Este controle deve partir, em primeiro lugar, do próprio Estado, que, ao produzir um ato administrativo, deve prestar atenção para que este atenda ao interesse público, ou, no caso de o serviço ter sido delegado ou se for serviço

11. Isto é, quando não estiverem atuando na posição de delegatárias. As empresas privadas podem atuar, assim, para a concretização de direitos fundamentais, como delegatárias de serviços públicos reservados ao Estado ou como prestadoras de serviços não reservados ao Estado, mas de relevância pública (saúde, lazer, educação etc.) - os chamados "serviços compartidos" -, podendo o Estado regulamentar, em ambos os casos, e também subsidiar e fomentar sua prestação, no intuito de torná-la mais eficiente. Ver, por exemplo: Aragão (2007, p. 703) e Barcellos (2007, p. 600). 
compartido, deve atuar de maneira regulativa, obrigando os entes privados a observarem o interesse público. Trata-se do autocontrole da Administração Pública, em que o Estado dá aos indivíduos pelo menos uma certeza teórica de que seus interesses estão sendo devidamente observados e que as políticas públicas estão sendo prestadas com eficiência (FrançA, 2008, p. 77). Além do autocontrole, devem existir, também, controles externos, até porque, na mais otimista das hipóteses, é possível que o controle interno falhe. Assim, é possível controle político pelo Poder Legislativo, podendo atuar, inclusive, junto com um Tribunal de Contas, naquilo que tange à fiscalização dos gastos e investimentos de recursos. Cabe também o controle judicial (SEabra Fagundes, 1957), ao qual cabe apreciar a legalidade dos atos editados e o cumprimento da Constituição. ${ }^{12}$ O Ministério Público também pode atuar, valendo-se, sobremaneira, de sua condição de fiscal do direito, para controlar a prestação de políticas públicas, utilizando-se dos meios que o ordenamento constitucional lhe dá para defender o interesse público. Por fim, aos cidadãos cabe, enquanto donos da coisa pública, individualmente ou através da sociedade civil, efetuar o chamado controle social, instrumento daquilo que os autores chamam de democracia participativa (VALADÉS, 1998, p. 2), por meio, por exemplo, de avaliações sobre a qualidade dos serviços prestados e acesso a informações sobre os atos do governo.

O controle da prestação de políticas públicas é, portanto, feito tanto no marco interno do próprio Estado, através, por exemplo, de revisões de ofício de seus atos ou de atividade regulamentar de órgãos criados para este fim, quando no marco externo, caso em que, por exemplo, as outras funções do poder estatal e seus auxiliares, além dos cidadãos, controlam não apenas, embora principalmente, a atuação da Administração Pública, mas também a ação dos particulares ao prestarem serviços de interesse público. Atua-se, portanto, como um "administrador negativo" (FREITAS, 2009, p. 45). E é mediante esse controle geral da Administração Pública que se deve observar se os recursos obtidos pelo Estado com o recolhimento de tributos são devidamente aplicados na consecução da finalidade precípua e primordial da máquina estatal representada no atendimento e proteção das necessidades humanas básicas, isto é, na concretização dos direitos fundamentais, sem que se apele, neste âmbito, para o discurso da reserva do possível e sem que se promova algum retrocesso social. Enfim, o controle busca atestar a eficiência do Estado na realização de suas atividades.

12. Este tipo de controle não seria necessário, a princípio, se as atividades prestacionais seguissem a legislação e observassem a Constituição, já que, se assim fosse, seria possível até falar em redução dos casos submetidos ao seu crivo e talvez até uma maior agilidade no julgamento de tipo de demandas. 


\section{Conclusões}

Concluindo, pode-se dizer que os indivíduos enquanto membros de uma sociedade e sujeitos ao Poder Estatal têm o dever de pagar tributos cujo montante será direcionado para a manutenção da máquina estatal e para a concretização de direitos fundamentais mínimos, isto é, pertencentes àquilo que se convencionou chamar de mínimo existencial. Efetivar esses direitos depende da atuação gerencial do Estado, que através de decisões administrativas, representadas especialmente pelo planejamento e pela realização de políticas públicas, gasta os recursos arrecadados alocando-os com eficiência. A realização desse mínimo existencial depende, portanto, de atos administrativos que prevejam uma dotação orçamentária própria, sem prejuízo de provisões para a manutenção do próprio Estado, mas em detrimento de gastos que não se revelem necessários ou para esta manutenção ou para aquela concretização. De aí a necessidade de haver o controle dos atos realizados pela Administração Pública, a fim de que se possa fiscalizar essa dotação financeiro-orçamentária, evitando-se que as escolhas feitas pelos agentes estatais vinculem o mínimo existencial ao discurso da reserva do possível, e de que os direitos fundamentais já concretizados não sejam submetidos a uma reversão quanto à sua realização.

Portanto, pode-se arrematar que a Administração Pública contemporânea, como parte da máquina estatal, tem como papel a necessária concretização e manutenção de pelo menos o conteúdo essencial dos direitos fundamentais, através da realização de políticas públicas, em parceria ou não com entidades privadas, empregando corretamente os recursos públicos que lhes são fornecidos pela sociedade em geral, a fim de que possam proporcionar aos indivíduos, especialmente àqueles que não têm condições ou não as têm suficientes, oportunidades de poder exercer sua autonomia e desfrutar de suas liberdades básicas. Na mesma quadra, os indivíduos têm o papel de financiar na medida de sua capacidade a construção de uma boa base de recursos públicos e de exigir do Poder Público, especialmente da Administração Pública, o correto emprego dessa verba para a concretização desses direitos.

Estabelecida esta relação, a sociedade e os indivíduos devem exigir do Estado, ou este tem a obrigação de adotar medidas de manutenção da concretização dos direitos, a fim de prestá-los com o fito de atingir um mínimo existencial, através de programas genéricos ou específicos, de acordo com a vulnerabilidade de setores da sociedade, proporcionando o exercício de uma dignidade sem retrocessos, para quaisquer pessoas. Além disso, o Estado também tem a obrigação de prestar contas à sociedade, demonstrando que os recursos arreca- 
dados foram corretamente previstos no orçamento para o seu uso na concretização eficiente de direitos fundamentais.

\section{REFERÊNCIAS BIBLIOGRÁFICAS}

Afonso da SiLva, V. Direitos fundamentais: conteúdo essencial, restrições e eficácia. São Paulo: Malheiros, 2009.

. O Judiciário e as políticas públicas: entre transformação social e obstáculo à realização dos direitos sociais. In: Souza Neto, C. P.; Sarmento, D. Direitos sociais: fundamentação, judicialização e direitos sociais em espécies. Rio de Janeiro: Lumen Juris, 2008.

Amaral, G. Direito, escassez \& escolha. Rio de Janeiro: Renovar, 2001.

Aragão, A. S. O conceito de serviços públicos no direito constitucional brasileiro. In: Souza Neto, C. P.; Sarmento, D. (coords.). A constitucionalização do direito: fundamentos teóricos e aplicações específicas. Rio de Janeiro: Lumen Juris, 2007.

Ataliba, G. Hipótese de incidência tributária. 6. ed. São Paulo: Malheiros, 2009.

ÁviLA, H. B. Teoria dos princípios: da definição à aplicação dos princípios jurídicos. 7. ed. São Paulo: Malheiros, 2007.

Bacellar Filho, R. F. O controle da administração pública. In: Cisneros Farías, G.; Fernández Ruiz, J.; López Olvera, M. A. (coords.). Control de la administración pública. Segundo Congreso Iberoamericano de Derecho Administrativo. Mexico: Unam, 2007.

BALBONI, E. Il concetto di "livelli essenziali e uniformi" come garanzia in materia di diritti sociali. Le Istituzioni del Federalismo. n. 6, 2001.

Bandeira de Mello, Carlos Antônio. Discricionariedade e controle jurisdicional. 2. ed. São Paulo: Malheiros, 2008.

"Relatividade" da competência discricionária. Anuario Iberoamericano de Justicia Constitucional. n. 8, 2004.

Barcellos, A. P. Constitucionalização das políticas públicas em matéria de direitos fundamentais: o controle político-social e o controle jurídico no espaço democrático. In: Souza Neto, C. P.; Sarmento, D. (coords.). A constitucionalização do direito: fundamentos teóricos e aplicações específicas. Rio de Janeiro: Lumen Juris, 2007.

BARNeS Vázquez, J. Introducción al principio de proporcionalidad en el derecho comparado y comunitário. Revista de Administración Pública. n. 35. p. 510, 1994.

Bernal Pulido, C. El principio de proporcionalidad y los derechos fundamentales. 3. ed. Madrid: Centro de Estudios Políticos y Constitucionales, 2007.

BuccI, M. P. D. Políticas públicas e direito administrativo. Revista de Informação Legislativa. n. 133, 1997.

Canotilho, José Joaquim Gomes. Direito constitucional e teoria da Constituição. 7. ed. Coimbra: Almedina, 2003. 
. Metodología "fuzzy" y "camaleones normativos" en la problemática actual de los derechos económicos, sociales y culturales. Derechos y Libertades. n. 6. p. 46, 1998.

Casalta Nabais, J. O dever fundamental de pagar impostos: contributo para a compreensão constitucional do estado fiscal contemporâneo. Coimbra: Almedina, 2004.

COASE, R. H. The problem of social cost. The Journal of Law and Economics. vol. 3. p. 17, 1960.

De Conto, M. O princípio da proibição do retrocesso social: uma análise a partir dos pressupostos da hermenêutica filosófica. Porto Alegre: Livraria do Advogado, 2008.

De Lucas, J.; Añón Roig, M. J. Necesidades, razones, derechos. Doxa. n. 7. p. $60,1990$.

Del Real, J. A.; Enríquez, G. J.; Rodrígues, L. G. Rodríguez (eds.). La maquinaria del derecho en Iberoamérica: constitución, derechos fundamentales y administración. México: Universidad Nueva de León, no prelo.

Derbli, F. O princípio da proibição de retrocesso social na Constituição de 1988. Rio de Janeiro: Renovar, 2007.

Di Pietro, M. S. Z. Discricionariedade administrativa na Constituição de 1988. 2. ed. São Paulo: Atlas, 2007.

França, P. G. O controle da Administração Pública: tutela jurisdicional, regulação econômica e desenvolvimento. São Paulo: Ed. RT, 2008.

Freire JR., A. B. O controle judicial de políticas públicas. São Paulo: Ed. RT, 2005.

FreItAS, J. Discricionariedade administrativa e o direito fundamental boa administração pública. 2. ed. São Paulo: Malheiros, 2009.

Galdino, F. Introdução à teoria do custo dos direitos: direitos não nascem em árvores. Rio de Janeiro: Lumen Juris, 2005.

Holmes, S.; Susntein, C. The cost of rights: why liberty depends on taxes. New York: W. W. Norton, 1999.

Immordino, G.; Pagano, M. The cost of rights: an economic analysis. Diritto \& Questioni Pubbliche. n. 4. p. 85, 2004.

Krell, A. J. Direitos sociais e controle judicial no Brasil e na Alemanha: os descaminhos de um direito constitucional "comparado". Porto Alegre: Sergio Antonio Fabris Ed., 2002.

. Realização dos direitos fundamentais sociais mediante controle judicial da prestação dos serviços públicos básicos (uma visão comparativa). Revista de Informação Legislativa. n. 144. p. 241, 1999.

Lopes, A. M. D. A garantia do conteúdo essencial dos direitos fundamentais. Revista de Informação Legislativa. n. 164, 2004.

Martins, L. (org.). Cinquenta anos de jurisprudência do Tribunal Constitucional Federal alemão. Montevideo: Fundação Konrad Adenauer, 2005. 
. Do vínculo do Poder Judiciário aos direitos fundamentais e suas implicações práticas. Revista da Escola Paulista de Magistratura. n. 2. p. 96, 2004.

Neuner, J. Os direitos humanos sociais. In: Sarlet, I. W. (org.). Jurisdição e direitos fundamentais. Porto Alegre: Livraria do Advogado, 2006. vol. 1. t. 1.

Ommati, J. E. M. Do ato ao processo administrativo: a crise da idéia de discricionariedade no direito administrativo brasileiro. Revista da Faculdade de Direito da UFOP, no prelo.

Peces-Barba Martínez, G. Los deberes fundamentales. Doxa. n. 4, 1987.

Peixoto, D. M. Competência administrativa na aplicação do direito tributário. São Paulo: Quartier Latin, 2006.

Pinheiro Faro, J. Os vinte anos da constituição brasileira: da reserva do possível à proibição do retrocesso social. In: ; Teixeira, B. C.; Miguel, P. C. Uma homenagem aos vinte anos da Constituição brasileira. Florianópolis: Boiteux/FDV, 2008.

Posner, R. A. The cost of rights: implications for Central and Eastern Europe And for the United States. Tulsa Law Journal. vol. 32. n. 1, 1996.

Prieto SAnchís, L. Los derechos sociales y el principio de igualdad sustancial. Revista del Centro de Estudios Constitucionales. n. 22. p. 15, 1995.

QueIroz, C. M. M. O princípio da não reversibilidade dos direitos fundamentais sociais: princípios dogmáticos e prática jurisprudencial. Coimbra: Coimbra Ed., 2006.

Robeyns, I. The capability approach: a theoretical survey. Journal of Human Development. vol. 6. n. 1. p. 94, 2005.

Rubio Llorente, F. Los deberes constitucionales. Revista Española de Derecho Constitucional. n. 62, 2001.

Sarlet, I. W. A eficácia dos direitos fundamentais: uma teoria geral dos direitos fundamentais na perspectiva constitucional. 10. ed. Porto Alegre: Livraria do Advogado, 2009.

Os direitos sociais como direitos fundamentais: contributo para um balanço aos vinte anos da Constituição Federal de 1988. In: Souza Neto, C. P.; Sarmento, D.; Binenbojm, G. (coords.). Vinte anos da Constituição Federal de 1988. Rio de Janeiro: Lumen Juris, 2008.

; Figueiredo, M. F. Algumas considerações sobre o direito fundamental à proteção e promoção da saúde aos 20 anos da Constituição Federal de 1988. Revista de Direito do Consumidor. vol. 67. p. 125. São Paulo: Ed. RT, jul. 2008.

SCAFF, F. F. Como a sociedade financia o estado para a implementação dos direitos humanos? In: Miranda Coutinho, J. N.; Bolzan de Morais, J. L.; Streck, L. L. (orgs.). Estudos constitucionais. Rio de Janeiro: Renovar, 2007.

. Reserva do possível, mínimo existencial e direitos humanos. In: Miranda Coutinho, J. N.; Barreto Lima, M. M. (orgs.). Diálogos constitucionais: direito, neoliberalismo e desenvolvimento em países periféricos. Rio de Janeiro: Renovar, 2006. 
SCHÄFER, J. Classificação dos direitos fundamentais: do sistema geracional ao sistema unitário: uma proposta de compreensão. Porto Alegre: Livraria do Advogado, 2005.

Seabra Fagundes, M. O controle dos atos administrativos pelo Poder Judiciário. 3. ed. Rio de Janeiro: Forense, 1957.

Sen, A. K. Desenvolvimento como liberdade. Trad. L. Teixeira Motta. São Paulo: Cia. das Letras, 2007.

Human rights and capabilities. Journal of Human Development. vol. 6. n. 2. p. 158, 2005.

Tavares, A. R. Curso de direito constitucional. 6. ed. São Paulo: Saraiva, 2008.

Torres, R. L. Curso de direito financeiro e tributário. 10. ed. Rio de Janeiro: Renovar, 2003.

ValadÉs, D. El control del poder. Mexico: Unam, 1998.

VAZ, A. R. A cláusula da reserva do possível como instrumento de efetivação planejada dos direitos humanos econômicos, sociais e culturais. Revista de Direito Constitucional e Internacional. vol. 66. p. 9. São Paulo: Ed. RT, jan. 2009.

Walzer, M. Esferas da Justiça: uma defesa do pluralismo e da igualdade. Trad. J. Simões. São Paulo: Martins Fontes, 2003.

Zimmerling, R. Necesidades básicas y relativismo moral. Doxa. n. 7, 1990.

Zockun, C. Z. Da intervenção do Estado no domínio social. São Paulo: Malheiros, 2009.

\section{Pesouisas do Editorial}

\section{Veja também Doutrina}

- A competência regulamentar e a reserva de lei revisão do enquadramento constitucional do espaço de concretização dos direitos sociais pela Administração Pública, de Bruno Moraes Faria Monteiro Belem - RT 912/21;

- Deveres como condição para a concretização de direitos, de Julio Pinheiro Faro RDCl 79/167; e

- Ilusões das vinculações de receitas e das despesas mínimas obrigatórias na efetivação dos direitos fundamentais, de André Castro Carvalho e Frederico Gonçalves Junkert RTA 4/211.

- Direitos fundamentais: conceito, função e tipos, de João dos Passos Martins Neto, São Paulo, Ed. RT, 2003; e

- Jurisdição constitucional e direitos fundamentais, de Georges Abboud, São Paulo, Ed. RT, 2011. 